\title{
Access and Utilization of Family Planning Methods Among Rural Women: The Case of Mirab Badawacho Woreda, Hadiya Zone, Southern Ethiopia
}

\author{
Elias Erkalo ${ }^{1}$, Yishak Gecho ${ }^{2}$ \\ ${ }^{1}$ Department of Rural Development and Agricultural Extension, Wolaita Sodo University, Wolaita Sodo, Ethiopia \\ ${ }^{2}$ Department of Rural Development and Agricultural Extension, College of Agriculture, Wolaita Sodo University, Wolaita Sodo, Ethiopia
}

Email address:

yishakgecho@yahoo.com (Y. Gecho)

\section{To cite this article:}

Elias Erkalo, Yishak Gecho. Access and Utilization of Family Planning Methods Among Rural Women: The Case of Mirab Badawacho Woreda, Hadiya Zone, Southern Ethiopia. Humanities and Social Sciences. Vol. 5, No. 2, 2017, pp. 60-68. doi: 10.11648/j.hss.20170502.12

Received: February 9, 2017; Accepted: February 25, 2017; Published: March 28, 2017

\begin{abstract}
This study was conducted at Mirab Badawacho Woreda. Its aim was to assess the status of access family planning information and utilization of family planning methods and to identify factors that determine the decision to utilize family planning methods among rural women. The total sample size for this study was 115 (53 family planning user and 62 non-user respondents). Quantitative data was analyzed by using descriptive statistics (frequency, percentage, mean and standard division), inferential statistics (chi-square and t-tests) and binary logit model. From the total 11 explanatory variables included in the binary logit model, health extension contact had significant and positive effect on the decision to utilize family planning methods at $1 \%$ significant level. While education level of respondents, annual gross income had significant and positive effect on the decision to utilize family planning methods at 5\% significant level whereas house type had significant and negative effect on the decision to utilize family planning methods at $5 \%$ significant level. However, attitude on family planning methods and access to NGOs support had significant and positive effect on the decision to utilize family planning methods at $10 \%$ significant level. Therefore, policy makers and family planning service providers should give due attention to determinants that significantly influencing the utilization decision of family planning methods through emphasizing women education and income improvement activities. Access to NGOs support had significant and positive effect on the decision to utilize family planning methods. Therefore, it should be better to create access to NGOs support for non-user women with special attention on intervention of family planning service. Attitude on family planning methods had significant and positive effect on the decision to utilize family planning methods. Therefore, it suggests provision of awareness creation training about the utilization of family planning methods for rural women. The significant and positive effect of Health extension contact on the decision to utilize family planning methods suggests improvement of the issues.
\end{abstract}

Keywords: Family Planning, Binary Logit, Hadiya Zone, Ethiopia

\section{Introduction}

According to Mengistu and others [1], Ethiopia is one of the countries with the highest maternal mortality, which is estimated at 871 per 100,000 live births. The major causes of maternal mortality and suffering are unsafe abortion, hemorrhage, and obstructed labor. With an estimated current population of Ethiopia nearly 87 million of which $83.8 \%$ live in rural areas and highly populous country in sub-Saharan Africa. The population is growing at a rate of 3.2 and is expected to reach over 173 million in 2050 [2]. Contraceptive prevalence in the country is very low with only $8 \%$ of married women using any type of contraception. This eventually leads to large numbers of unwanted pregnancies every year.

According to Eltomy and Saboula [3], a woman's ability to space and/or limit her pregnancies has a direct impact on her health and well-being as well as on the outcome of each pregnancy. Family planning (FP) is a major contributing factor towards child survival and reduction in maternal 
mortality. The relevance of FP in any strategy for safe motherhood and child survival is undeniable. More than 100 million women in the less-developed countries, about $17 \%$ of all married women, would prefer to avoid pregnancy, but are not using any form of FP. Unmet need for contraception can lead to unintended pregnancies, i.e. either unwanted or mistimed, which poses risks for women, their families and society.

The population growth in Ethiopia was recorded at an average of 2 million annually between 2000 and 2005, representing a rate of 2.73 percent, which is slightly higher than the SSA average of 2.5 percent. The population is largely rural (83 percent) and young, with 44 percent under the age of 15 . Such a structure results in a high dependency ratio as well as a future rapid exponential population growth [4].

In Ethiopia, modern family planning services were introduced by the Family Guidance Association of Ethiopia (FGAE) in 1966. In the 1980s the Ministry of Health of Ethiopia incorporated family planning with the maternal and child health services. The primary Population plan of Ethiopia adopted in 1993 targeted 4 children per woman and increasing the contraceptive prevalence rate to $65 \%$ by the year 2015. Later on, the National Office of Population was established to implement and oversee the strategies and actions related to family planning, since the adoption of the National Population Policy, a favorable environment has been created for expanding family planning programs in the country [5]. Family planning contributes significantly to reduce fertility and thereby maintain high and unintended population growth which has been negatively affecting the development of a nation where there is steady and low economic development. Family planning is one of the subprograms of population policy particularly of the populous developing Countries.

Family planning has multiple advantages for people especially women and children of poor nations, to trap from servitude and miserable situation they are in. The benefits of family planning extend beyond slowing the pace of population growth and Family planning is also cost-effective by reducing a woman's exposure to unintended pregnancies, family planning saves lives and costs less than maternity-care services [6]. Ways of examining fertility trends is to compare current status with past from the three earlier Ethiopian demographic and health survey surveys. So that fertility trends over the last fifteen years data show that the Total Fertility rate (TFR) decreased only slightly from 5.5 children in 2000 to 5.4 children in 2005 , with a more pronounced decline to 4.8 children in 2011 [2].

The provision of the family planning service is one of the important strategies for reducing maternal morbidity and mortality worldwide and as well as to control rapid population growth [7]. Recognizing these facts the government of Ethiopia launched a National Population Policy in April 1993. The purpose of the Population Policy is to keep balance between the size of the population and the country's resource base and thereby improve the health status of the people. To this end, the focus of the strategy is, on high fertility rates; and in the policy emphases has been given on increasing the level of mother and child health care provision, (including family planning services) and educating women as the main contributors in controlling rapid population growth the country is facing and to improve health condition of the population [8].

The purpose of the population policy of Ethiopia is to complement the rate of population growth with socioeconomic development to achieve a high level of wellbeing. in the middle of others, the specific objectives of the policy have been: decrease the total fertility rate from 7.7 children per woman in 1990 to 4.0 children per woman in 2015 , increase the prevalence of contraceptives from 4 percent in 1990 to 44 percent in 2015; reduce maternal, infant and child morbidity and mortality rates as well as promote the level of general welfare of the population, rise an effective countrywide population information and education program addressing issues pertaining to small family size and its relationship with human welfare and environmental security [8].

As indicated in policy and in the targets of MDGs the country entered promise to reduce the total fertility rate from 7.7 children per woman in 1990 to 4.0 children per woman in 2015. However, the fertility rate per women was 6.4 in rural as compared to 3.3 of towns [9]. This is a clear indicator to give a particular attention and priority to address the issues in the rural areas. As vast majority of people are dwelling in the rural areas (about 85\%) unless proper measures shall be taken based on research findings, attaining the planned targets of the population policy. In addition, Total Fertility Rate (TFR) variation has been observed among the regional states of Ethiopia. According to CSA and ORC [9], there is substantial difference infertility by regions ranging from a low of 1.4 children per woman in Addis Ababa to a high as 6.2 children per woman in Oromiya; and when compared with TFR of 5.2 children of the country it is high and totally very high in rural parts of the region.

There are many studies which showed that the rural poor have not been benefiting from the family planning and related services to the level expected, and that family planning programs have not being addressing the poor. The same study confirmed that as there is a strong relationship exists (in Ethiopia) between demographic characteristics and the probability of a household being poor. Among many, factors that hamper or prevent the rural and the poor not to get the service of family planning have been: couples do not know about contraception, cultural values may support high fertility, a woman's low status relative to her husband and other family members may limit her ability to use family planning; and lack of access to choices regarding contraceptive methods. The Study area population growth rate is $2.9 \%$ per annum which is higher than the expected level [4] and highly populated in central zone's of the region. So that population size and economic growth is not complement to. Because of this the study area is characterize with high poverty which shows great number of food aid and 
safety net beneficiaries.

Mirab Badawacho Woreda (the study area) is one of the Woredas (districts) found in Hadiya Zone of Southern Nation Nationality and Peoples Region. The Woreda is one of the most populous woredas with high density (184 persons $/ \mathrm{km}^{2}$ ) in Hadiya zone [10]. In the Woreda most of rural women were not obtaining adequate benefits from family planning services; women and children have been exposed to hardships and difficulty because of the problems related to high fertility rate and poor reproductive health service status as compared to urban people.

For instance, according to Mirab Badawacho Woreda health Office the average number of children per women of the Woreda was 5.6 and it is greater than five in rural when compared to urban. However, contrary to this, the mission of family planning is to serve all people equally at all places (rural and urban). According to FMOH [11], the aim of the family planning program is to increase family planning services access to all persons at the age of puberty and married couples to make them know about the correct information of family planning and raise their awareness on the types and utilization of different contraceptives so that they benefit from the available services depending on their choices. The expected results/outputs of family planning extension package include adequate information and utilization of family planning services by the households are the major areas of the targets to be realized. Ensuring utilization of family planning information and methods to the community is the central issue in the realization process of the family planning extension package.

In the study area there was lack of knowhow about the status of access to family planning information and utilization of different family planning methods. On the other side, in the area lack of understanding about different determinant factors that influence the decision to utilize family planning methods. Additionally, in the area there was no study conducted on the utilization of family planning methods. Therefore, this study was designed to fill the gap, aimed to assess the access and utilization of family planning methods and to identify factors that determine the decision to utilize family planning methods among rural women.

\section{Research Methodology}

\subsection{Description of the Study Area}

Mirab Badawacho, the study area, is one of 10 Woredas (districts) in Hadiya Zone which found in the Southern Nations, Nationalities and Peoples Region (SNNPR). It is bordered with Kambata Tambaro Zone north and north-east and east by Misrak Badawacho and with south by Wolaita Zone and with northwest Kachabira Woreda. And it is located about $357 \mathrm{~km}$ south west of the Capital city of the country and $127 \mathrm{~km}$ from the regional Capital, Hawassa. It has total of 21 peasants associations and 1 urban kebele (small administrative units). The average elevation of 1756$2000 \mathrm{~m}$ above sea level.

Agriculture is the main occupation of the people of study area. It is mainly rain-fed, although it is supplemented by small scale irrigation. It has become almost impossible to produce enough as the area is facing frequent failure of rain. The major crops grown in most of the area are Teff, Maize, Haricot beans, Enset and cassava. Coffee and Chat are also grown as Cash crops. The area has an annual mean temperature ranges from about $18^{\circ} \mathrm{C}$ to $21^{\circ} \mathrm{C}$.

Health infrastructure situation of the wereda is, there are, four health centers, and 22 health posts that provide basic health care and family planning services. The family planning services include information, education, and communication about contraceptives, birth spacing and controlling, counseling on use of birth control methods the supply of contraceptives. Any women or men interested can get the service by contacting the service providers or go to service centers. Family planning services are given to users free of charge. Health extension workers visit homes of individuals to provide health education including family planning. All health extension workers are female ones. At health center and clinics, the service is provided by nurses and public health officers while at health posts it is given by health extension.

\subsection{Sampling Technique and Sample Size Determination}

Making proper and good decision is the first step in selecting sampling unit. A correct sample size related with different factors including time, cost, and degree of accuracy [12]. Taking too specific samples limit our scope of investigation and on other hand taking too large sample things get out of control and become general. It is good to collect right amount sample size, so the one will get good representative data. This study was applied a simplified formula provided by Ymane [13] as cited by Twodros [14], to determine required sample size at $95 \%$ confidence level, 0.5 degree of variability and $0.09 \%$ level of precision.

For the purpose of this study a multi-stage sampling technique was used to select sample respondents. In the commencement of the sampling, from the total woreda's of Hadiya Zone MirabBadawacho woreda (district) was purposively selected because it is densely populated woreda in the zone with 184 people per $\mathrm{km}^{2}$.

In the second stage, 22 kebeles (small administrative units in local area) were categorized into two groups based on distance from town. Those kebeles located in less than and 7 kms radius from towns and have accessible roads and transport were categorized as close kebeles. On the other hand, those kebeles located in more than $9 \mathrm{~km}$ radius from nearby towns were classified as far kebeles.

In the third stage lists of kebeles of the two categories were prepared and random sampling technique (two sample kebeles from close and two sample kebeles from far) a total of 4 kebeles for the study purpose were chosen. Further, the populations in 4 kebeles were stratified into two strata: user 
and non-user of family planning methods. A list of user and non-user were taken from health posts of respective kebeles.

Finally, the lists of the total women of both strata (users and non-users) were prepared and then 53 users and 62 nonusers were selected by simple random sampling techniques from lists taken into consideration probability proportional to size. As result a total of 115 sample respondents were used for the study.

\subsection{Sources and Methods of Data Collection}

Both primary and secondary data sources were employed for the study. Relevant primary data was gathered from rural women at household level and key informant. Secondary data were collected on from the sources like woreda office of health, health posts and health centers.

Primary data was collected using a structured interview schedule. The interview schedule was pr-tested and modification was done in the light of suggestion and context of the area before conducting the survey. Eight enumerators, who can speak local language (Hadysaa) were employed; all of them had diploma.

Before survey work began, the enumerators were given training on contents of the questionnaire, how to approach the respondent and on methods of data collection. Finally, the structured survey instrument was administered under the close supervision of the researcher. Besides, secondary data was also collected from relevant organizations.

\subsection{Methods of Data Analysis}

In this study, descriptive statistics, inferential and econometric models (binary logit) was used to analysis the data with the help of SPSS 16.

\subsubsection{Descriptive Statistics}

Descriptive statistics like frequency, percentage, mean and standard division were employed for the description of different demographic, socio -economic; psychological and institutional characteristics of the sample respondents.

Moreover, inferential statistics like chi-square test was used to test the statistical significances of the categorical variables while t-test was employed for continuous variables.

\subsubsection{Econometric Models Specifications}

For the purpose of the study binary logit model was used for analysis of factors that affecting utilization decision of family planning methods. Selection of binary models follow that individuals faced a choice of two alternatives and their choice depend on their characteristics. Hence, the objective of a binary choice model is to decide the probability that an individual within the given set of options will do one choice rather than the alternative.

Following Gujarati (1995); the functional form of logit model is specified as follows:

$$
P_{i}=\mathrm{E}(Y i / X i)=\frac{1}{1+e^{-\left(\beta_{0}+\beta_{1} X_{i}\right)}}
$$

We can write the above equation as follow

$$
P_{i}=\mathrm{E}\left(\frac{\mathrm{Yi}}{\mathrm{Xi}}\right)=\frac{1}{1+e^{-Z_{i}}}
$$

Where $P_{i}=$ is the probability of being using or not using family planning methods

$$
\mathrm{Z}_{i}=\beta_{0}+\sum_{i=1}^{m} \beta_{i} \mathrm{x}_{i}, \mathrm{i}=1,2,3 \text {----------m }
$$

$\beta_{\mathrm{o}}=$ is an intercept

$\beta_{\mathrm{i}}=$ are slopes of the equation

$\mathrm{X}_{\mathrm{i}}=\mathrm{n}$ explanatory variables, in this particular study, it represents 11 independent variables.

$$
1-\mathrm{Pi}=\frac{1}{1+e^{Z_{i}}}
$$

Therefore, we can write two equations together as

$$
e^{Z_{i}}=\frac{P_{i}}{1-P_{i}}=\frac{1+e^{Z_{i}}}{1+e^{-Z_{i}}}
$$

Then, equation (6) is simply the odds ratio in favor of FP utilization.

Finally, taking the natural $\log$ of equation (5) we obtain

$$
\mathrm{Li}=\ln \left(\frac{P_{i}}{1-P_{i}}\right)=\beta_{0}+\beta_{1} X_{i}
$$

The logit model becomes

$$
\mathrm{Zi}=\beta \mathrm{o}+\beta_{1} \mathrm{X}_{1}+\beta_{2} \mathrm{X}_{2}+\ldots \ldots \ldots+\beta \mathrm{nXn}+\mathrm{Ui}
$$

$\mathrm{L}_{\mathrm{i}}=$ is $\log$ of the odds ratio, which is not only linear in $X_{i}$ but also linear in the parameters.

$\mathrm{X}_{\mathrm{i}}=$ Vector of relevant explanatory variables.

The Dependent Variables

Women's decision to use family planning method: it is a dummy variable, representing family planning utilization decision. In relation to this, woman who is currently using or used modern birth control methods in her life to delay or to space or to limit birth were considered as family planning user (1). Rural woman who did not use modern birth control methods for any of the three purposes of family planning in her life were considered as non-users (0). For analysis of the variable the binary logit model was used. 
Table 1. The summary of explanatory variables, description their measurements and expected relationship with dependent variable.

\begin{tabular}{lllll}
\hline No & Independent Variables & Variable Types & Units of Measurement & Expected sign \\
\hline 1 & Age of respondents & Continuous & Year & + \\
2. & Number of children & Continuous & Number & + \\
3. & Education status & Continuous & Grade level & + \\
4. & Access to NGOs support. & Dummy & 0 and 1 & + \\
5. & Decision making power. & Dummy & 0 and 1 & - \\
6. & Type of house & Dummy & 0 and 1 & + \\
7. & Attitude towards FPM. & Dummy & 0 and 1 & + \\
8. & Contact to HEAs & Continuous & Frequency & + \\
9 & Training & Dummy & 0 and 1 & + \\
10 & Annual gross income & Continuous & Birr(ETB) & - \\
\hline
\end{tabular}

\section{Results and Discussions}

\subsection{The Sources and Types of Family Planning Methods}

\subsubsection{Sources of Birth Control Service}

People in the study area uses different sources to access birth control methods. The result in Table 2 shows that from the total user respondents, about $88.7 \%$ used birth control services form health posts and $7.5 \%$ from public health center and the remaining (3.8\%) from NGOs and Hospitals. This result revealed that majority of family planning users get birth control services from health posts. In addition to this, public health center also plays major role in providing birth control services for rural women.

Table 2. Sources of birth control service provision.

\begin{tabular}{lll}
\hline \multicolumn{3}{c}{ Sources N\% } \\
\hline NGOs & 1 & 1.9 \\
Public health center & 4 & 7.5 \\
Health posts & 47 & 88.7 \\
Hospital & 1 & 1.9 \\
\hline
\end{tabular}

Source: Own field survey, 2016.

\subsubsection{Types of Contraceptive Methods Used}

The result in Table 3 shows that in last two years from the total user respondents, about $79.2 \%$ respondents have used implantable contraceptive method while, $17 \%$ have used injection contraceptive method and the remaining 3.8\% have used pills and tubaligation contraceptive methods. These results also revealed the majority of family planning user respondents have used implantable contraceptive method last two years. Additionally, these results imply that in the study area the majority rural women have preferred implantable birth control methods.

Table 3. Types of contraceptive methods used by the respondents last two years.

\begin{tabular}{lcc}
\hline & Types of contraceptive methods used N\% \\
\hline Implantable & 42 & 79.2 \\
Injection & 9 & 17 \\
Pills & 1 & 1.9 \\
Tubaligation & 1 & 1.9 \\
\hline
\end{tabular}

Source: Own field survey, 2016.

\subsection{The Descriptive Statistics Results of Explanatory Variables}

In this section, the sample households' demographic, socio-economic, psychological and institutional characteristics were discussed so as to understand the variation of different characteristics between the sampled respondents and the relationship with the use of family planning methods. Such analysis is essential to ensure an understanding of the context in which results were obtained.

According to the descriptive statistics some variation were observed between the users of family planning and non-users in terms of demographic, socio-economic and institutional factors. The two groups differ to some extent in educational level, type of house, frequency of contact by health extension agent, attitude on contraceptive methods, income, access to NGO support and land size.

The mean value of educational attainment by the users of family planning is greater than non-users (Table 4). The tvalue shows that there was significant mean difference in the education level of respondents between two groups. This significance variation revealed that women who had better educational level were in better position to decide use of family planning methods. This indicates educational role in improving awareness and understanding about birth control methods. This finding is similar with the study conducted by Haile [15], Bonge [16] and Firaole [17]. Similarly, in terms contact with health extension agent, the users group made more contact with health extension agent. In this regard, the mean value of extension contact made by users was 2.26 while, it was only 1.63 for non-users. This implies that the users of family planning contacted more frequently than nonusers (Table 4). The t-value also shows that there was significant mean variation between two groups in frequency of contact with Health Extension Agents at 1\% probability level. This significance revealed that the mean variation between two groups has its own implication on the utilization decision of family planning methods. Therefore, women who have high contact with health extension agent have preferred more to use family planning methods.

The variation between two groups was also observed in terms house types. More proportion (74.2\%) of user respondents live in corrugated iron roofed houses while, contrary to this, large part of non users $(56.6 \%)$ live in grass 
roofed houses (Table 5). The chi-square value shows that there was significant relationship between house type and use of family planning methods at $1 \%$ probability level. This significance relationship revealed that the variation in house type between two groups has its own implication on the utilization decision of family planning methods. Therefore, poor housed women have highly preferred the use of family planning methods due to their poor economic status and potential. As the survey result indicates, household annual gross income makes different between family planning users and non-users. The mean annual income of the user respondents greater than non-users, in which users generated 6896.53 Birr per annual while it was 5703.08 for non users. The t-value also shows that the mean of annual gross income obtained by user respondents' household was significantly differs and better than that was obtained by non-user respondents' household at $5 \%$ probability level. This significance variation in annual gross income between two groups has its own implication on the utilization decision of family planning methods. Therefore, the women who get more income are highly preferred to decide to use family planning methods. The finding of study is similar with research works of Haile [15]; and Amha and Enquesilassie (18).

NGOs Support also played great role in using family planning methods. As the data shows, about $56.6 \%$ of user respondents and $24.2 \%$ of non-user respondents had access to NGOs support in the area (Table 5). This result shows that those women who had access to NGOs support used family planning methods more. The chi-square value shows there was significant relationship between respondents' access to NGOs support and use of family planning methods that at $1 \%$ probability level. Therefore, this significance relationship revealed that women who had access to NGOs support in the area have highly preferred to use family planning methods.

Table 4. Descriptive statistics for continuous explanatory variables.

\begin{tabular}{|c|c|c|c|c|c|c|c|}
\hline \multirow{3}{*}{ Variable } & \multicolumn{6}{|c|}{ Respondent category } & \multirow{3}{*}{ T-test } \\
\hline & \multicolumn{2}{|c|}{ User } & \multicolumn{2}{|c|}{ Non-User } & \multicolumn{2}{|l|}{ Total } & \\
\hline & Mean & SD & Mean & SD & Mean & SD & \\
\hline Age & 24.89 & 8.047 & 23.92 & 5.424 & 24.37 & 6.746 & 0.765 \\
\hline Education & 6.17 & 3.46 & 3.26 & 2.36 & 4.6 & 3.25 & $5.33 * * *$ \\
\hline Number of children & 4.49 & 1.846 & 4.08 & 2.098 & 4.27 & 1.98 & 1.103 \\
\hline Health extension contact & 2.26 & 0.524 & 1.65 & 0.63 & 1.93 & 0.659 & $5.669 * * *$ \\
\hline Total annual income & 6896.53 & 3223.08 & 5703.08 & 2391.2 & 6253.1 & 2855.7 & $2.274 * *$ \\
\hline
\end{tabular}

Source: Own field survey of $2016^{*}, * * * * *$, Significant at $10 \%, 5 \%$ and $1 \%$ respectively.

In terms of land size, the average farm size of family planning users was more than non-users. The mean land holding of user respondents' household and non-user respondents' household were 0.46 and 0.43 respectively. The t-value also shows that the mean land holding by user respondents' household was significantly differs and less than that was obtained by non-user respondents' household at $10 \%$ probability level. This significance variation in mean land holding between two groups has its own implication on the utilization decision of family planning methods. Therefore, large mean land holding women had less preferred to decide to use family planning methods. Caldwell et al. [19] reported that in Thailand smaller land sizes have facilitated the adoption of contraceptive methods implying that there is some relationship between land size and contraceptive use. Maglad [20] concluded in his study on effect land size on fertility in rural Sudan that the land size is negatively related with the use of birth control methods.

Table 5. Descriptive statistics for dummy variables.

\begin{tabular}{|c|c|c|c|c|c|c|c|c|}
\hline \multirow{3}{*}{ Variable } & \multirow{3}{*}{ Response } & \multicolumn{6}{|c|}{ Respondent category } & \multirow{3}{*}{ Chi square -test } \\
\hline & & \multicolumn{2}{|c|}{ User } & \multicolumn{2}{|c|}{ Non-User } & \multicolumn{2}{|c|}{ Total } & \\
\hline & & $\mathbf{N}$ & $\%$ & $\mathbf{N}$ & $\%$ & $\mathbf{N}$ & $\%$ & \\
\hline \multirow{2}{*}{ Participate in training } & Yes & 5 & 9.4 & 7 & 11.3 & 12 & 10.4 & \multirow[t]{2}{*}{0.1} \\
\hline & No & 48 & 90.6 & 55 & 88.7 & 103 & 89.6 & \\
\hline \multirow{2}{*}{ Types of house } & Grass roofed & 23 & 43.4 & 46 & 74.2 & 69 & 60 & \multirow[t]{2}{*}{$-11.29 * * *$} \\
\hline & Corrugated Ironroofed & 30 & 56.6 & 16 & 25.8 & 46 & 40 & \\
\hline Decision making power & Yes & 33 & 62.3 & 38 & 61.3 & 71 & 61.7 & 0.044 \\
\hline \multirow{2}{*}{ Access to NGOs support } & Yes & 30 & 56.6 & 15 & 24.2 & 45 & 39.1 & \multirow[t]{2}{*}{$12.6 * * *$} \\
\hline & No & 23 & 43.4 & 47 & 75.8 & 70 & 60.9 & \\
\hline
\end{tabular}

Source: Own field survey of 2016 . Note: $* * *$, indicates Significance at $1 \%$ level.

\subsection{Attitude on Contraceptive Methods}

The results in Table 6 show that from the total respondents $45.2 \%$ had positive attitude and $54.8 \%$ had negative attitude on the use of contraceptive method.
However, $73.6 \%$ of user respondents have positive attitude on the use of contraceptive methods, while $21 \%$ of nonuser respondents had positive attitude on the use of contraceptive methods. On the other hand, about $26.4 \%$ of user respondents had negative attitude on contraceptive 
methods and $79 \%$ of non-user respondents had negative attitude on contraceptive methods. This result also revealed that more than half of respondents had negative attitude on the use of contraceptive method. However, the majority of family planning user respondents had positive attitude whereas the majority of non-user respondents had negative attitude on contraceptive methods. The chisquare value shows that there was significant relationship between attitude and use of family planning methods at $1 \%$ probability level. This significance relationship revealed that the attitude variation between two groups has its own implication on the utilization decision of family planning methods. Therefore, women who had positive attitude have highly prefer to use family planning methods. The result is similar with Wegene and Enquesilassie [21].

Table 6. Attitude on contraceptive methods.

\begin{tabular}{llllllll}
$\begin{array}{llllll}\text { Respondents' } \\
\text { Attitude }\end{array}$ & User & & \multicolumn{2}{c}{ Non-user } & \multicolumn{2}{l}{ Total } & \multicolumn{2}{c}{$\begin{array}{l}\text { Chisquare } \\
\text { value }\end{array}$} \\
\cline { 1 - 6 } Positive & $\mathrm{N}$ & $\%$ & $\mathrm{~N}$ & $\%$ & $\mathrm{~N}$ & $\%$ & \\
Negative & 39 & 73.6 & 13 & 21 & 52 & 45.2 & \\
\hline
\end{tabular}

Source: Own field survey of 2016. P-value $=0.000^{* * *}$, Significant at $1 \%$ level.

\subsection{Logit Model Result on Determinants of Family Planning Utilization}

In this section, selected explanatory variables were used to estimate the logistic regression model to analyze the determinants of utilization of family planning methods. A logit model was fit to estimate the effects of the hypothesized explanatory variables on the probabilities of family planning utilization.

Finally, a set of 11 explanatory variables ( 6 continuous and 5 discrete) were included in the logistic analysis. These variables were selected on the basis of theoretical explanations, personal observations and the results of the survey studies. To determine the best subset of explanatory variables that are good predictors of the dependent variable, the logistic regression were estimated using the method of maximum likelihood estimation, which is available in statistical software program (SPSS version 16). All the above-mentioned variables were entered in a single step. The definition and unit of measurement of the variables used in the model are presented in Table 1.

Table 7. The binary logistic regression results of Utilization of family planning methods.

\begin{tabular}{llllll}
\hline Variable & Coef & S. E & Wald & Sig & Odds ratio \\
\hline Age & 018 & 039 & 221 & 638 & 1.018 \\
LEDU & 258 & 106 & 5.941 & $015^{* *}$ & 1.295 \\
NMCH & 173 & 151 & 1.320 & 251 & 1.189 \\
TYH(1) & -1.279 & 629 & 4.131 & $042^{* *}$ & 278 \\
SIZLAN & -.144 & 861 & 028 & 867 & 866 \\
AOINCOME & 000 & 000 & 5.801 & $016^{* *}$ & 1.000 \\
DECMP & -.702 & 631 & 1.238 & 266 & 496 \\
\hline
\end{tabular}

\begin{tabular}{llllll}
\hline Variable & Coef & S. E & Wald & Sig & Odds ratio \\
\hline FRVIHEX & 2.138 & 633 & 11.392 & $001^{* * *}$ & 8.483 \\
PATRAIN & 1.252 & 1.111 & 1.271 & 260 & 3.499 \\
ACNGO & 1.124 & 608 & 3.417 & $065^{*}$ & 325 \\
Attitude & 1.220 & 685 & 3.171 & $075^{*}$ & 295 \\
Constant & -7.075 & 2.431 & 8.472 & 004 & 001 \\
Correctly predicted & 81.1 & & & & \\
user & & & & & \\
Correctly predicted & 87.1 & & & & \\
non-user & 84.3 & & & & \\
Overall percentage & $8.677^{* * *}$ & & & \\
Chi-square value & 76.670 \\
-2log likelihood & 82.042 & & & & \\
Sample size & 115 & & & & \\
\hline
\end{tabular}

Source: Computed from field survey data, 2016. Note: *, **and *** represent significant at $10 \%, 5 \%$ and $1 \%$ level respectively.

The logit model results used to study factors influencing the utilization decision of family planning methods are shown in Table 7. Among the 11 variables used in the model, 6 variables were significant with respect to utilization of family planning methods with less than $10 \%$ of the probability level. These variables include education level (LEDU), total annual income (AOICOME), house type (TYH), frequency of health extension agent contact (FRVIHEX), access to NGOs support (ACNGO) and women's attitude towards family planning methods (ATTITUDE), whereas the rest 5 explanatory variables were found to have no significant influence on utilization. The effect of the significant explanatory variables on the utilization decision of family planning methods in the study area is discussed below:

Level of education of the women: the variable was significant at 5\% significance level and positively related with family planning methods utilization decision among rural women in the study area. This implies that all other things being kept constant, the odds ratio support of showing interest to use family planning methods increases by a factor of 1.295 for the education level of women increased by one level.

Therefore, more educated women have more decided to use family planning methods when compared with less educated women in the study area. In agreement with this finding of Ibnouf et [17], reported that education level had a statistically significant influence on the odds of the respondents using modern methods of contraception. Compared with those with no schooling; those with education were significantly more likely to report using contraception $(P=0.003)$. On the other side, Jeeleebhoy [22], reported that female education is a key determinant of contraceptive use, as seen at both macro levels and the individual level by virtue of their decisions making authority; more educated women are in a better position than less educated women to make reproductive and contraceptive decisions; their control over resources and their ability to operate in the outside world and enables them access to services better; their spousal communications and intimacy allow them to overcome shyness in making contraceptive decisions. On the other hand similar study conducted by 
USAID [23], reported that contraceptive use increases with increased educational attainment. Nearly half of women who had at least some secondary education use a modern method, in contrast to $10 \%$ of women with no education.

Access to NGOs support of women: the variable showed significant and positive relation with the decision to use family planning methods at $10 \%$ level of significance. Those women who have access to NGOs support to obtain health services found to be more decided to use family planning methods as compared to those who have no access. As it is presented in Table 7, the odds ratio in favor of reaching decision to use family planning methods increases by a factor of 0.325 for those rural women who have access to NGOs support to obtain health services; holding other factors constant.

Therefore, those women who have access to NGOs support to obtain health services more decided to use family planning methods when compared with those who have no access to NGOs support to obtain health services in the study area. The result obtained from key informant interview revealed that in the study area the access to NGOs support to obtain health services increases the women's access to information about family planning; the communication and contact with health extension agents as well as improve awareness about different contraceptive methods. Consequently increase their interest to use of family planning methods.

Attitude of women on family planning methods: The result of the study confirmed the prior expectation that at $10 \%$ significant level it affects positively and significantly family planning method utilization decision among rural women in the study area. The model result indicated that those women who have favorable/positive attitude found to be more decided to use family planning method as compared to those women who have unfavorable/negative attitude towards family planning methods.

The model result also showed that, the odds ratio in favor of reaching on decision to use family planning methods increases by a factor of 0.295 for those rural women who have favorable attitude towards family planning methods, keeping other things constant. In agreement with this finding Belaineh. et al., [24], the study has conducted on Addis Ababa University Female Students indicated that positive attitude towards emergency contraceptive had positive relation with utilization.

Annual gross income of respondents' household: Annual gross income had significant positive effect on the utilization decision of family planning methods at 5\% significant level. The odds ratio in favor the use of family planning methods increases by a factor of 1 for the respondents' household who had better annual gross income. Therefore, the respondents' household who had higher annual gross income has more decided to use family planning methods. The finding of study is similar with research works of Amha and Enquesilassie [18].

Type of house: had significant and negative effect on the utilization decision of family planning methods at $5 \%$ significant level. The odds ratio disfavor the use of family planning methods decreases by a factor of 0.278 for the respondents' household who had corrugated iron roofed house. Therefore, the respondents' household who had better house type has less decided to use family planning methods. Because of their housing types shows their economic potential and their livelihood level. Accordingly, better-off household need extra children Tilahun [25] reported similar finding.

Health extension contact: had significant and positive effect on the utilization decision of family planning methods at $1 \%$ significant level. The odds ratio in favor the use of family planning methods increases by a factor of 8.483 for the respondents' household who had better contact with heath extension agent. Therefore, the respondents' household who had better contact has more decided to use family planning methods. Because of the extension contact improves women's access to information and creates awareness about different birth control methods utilization. Asres [26] reported similar finding. Therefore, from the total discussed above six determinant factors; health extension contact had relatively most significant and positive effects on the utilization decision of family planning methods at $1 \%$ significant level when compared with other determinant factors.

\section{Conclusion and Recommendation}

The provision of the family planning service is one of the important strategies to control rapid population growth. Even though the utilization of the methods among rural community is determined by various factors. The binary logit model result shows that health extension contact had significant and positive effect on the decision to utilize family planning methods at $1 \%$ significant level. While education level of respondents, annual gross income had significant and positive effect on the decision to utilize family planning methods at 5\% significant level whereas house type significant and negative effect on the decision to utilize family planning methods at 5\% significant level. However, attitude on family planning methods and access to NGOs support had significant and positive effect on the decision to utilize family planning methods at $10 \%$ significant level.

In the study area the major source of information for women about family planning services were health extension agents. However, the frequency of getting information about family planning services from available sources was less.

The possible solutions suggested are as follows:

- Targeting the identified determinant factors, and making policy and development interventions can promote the level of utilization of family planning among rural women in the study area. Therefore, policy makers and family planning service providers should give due attention to determinants that significantly influencing the utilization decision of family planning methods through emphasizing women education and income improvement activities. 
- Access to NGOs support had significant and positive effect on the decision to utilize family planning methods. Therefore, it should be better to create access to NGOs support for non-user women with special attention on intervention of family planning service. Because it improves the decision to utilize family planning methods.

- Attitude on family planning methods had significant and positive effect on the decision to utilize family planning methods. Therefore, it should better to provide awareness creation training about the utilization of family planning methods for rural women. Since, when their attitude will be positive, they highly decide to use family planning methods.

- Health extension contact had significant and positive effect on the decision to utilize family planning methods. Therefore, it should better to increases women's contact through provision of incentives to motivate them. Then which creates awareness about the utilization of family planning methods for rural women.

\section{References}

[1] Mengistu Asnake1, Lakachew Walie2, Yilma Melkamu3, 2006. Improving the range of contraceptive choices in rural Ethiopia MOH, 2003. Family Planning Extens Package.

[2] EDHS (Ethiopian Demographic and Health Survey), 2011. National Guideline for Family Planning in Ethiopia. Ministry of Health, Addis Ababa, Ethiopia EDHS (2011).

[3] Eltomyand Saboula, 2013. Barriers affecting utilization of family planning services among rural Egyptian women.

[4] CSA, 2013. South nation, nationalities peoples region Bureau of of statistics and population, SNNPR, BOSP 2013.

[5] EMOH (Ethiopian Ministry of Health) 2011. National Guideline for Family Planning in Ethiopia. Addis Ababa, Ethiopia EDHS (2011).

[6] Vidya and Ushma, 2002. Birth Spacing: Three to Five Saves Lives. Population Reports: Johns Hopkins Bloomberg School of Public Health, Population Information Program.

[7] WHO, 1999. Reduction of Maternal Mortality. A Joint WHO/UNFPA/UNICEF/World.

[8] TGE, 1993. National population policy of Ethiopia. Addis Ababa, Ethiopia.

[9] Central Statistical Office and ORC Macro, 2006. Ethiopian Demographic and Health Survey, (EDHS) 2005. [On-line]. Available: httt://cnhde. ei. columbia. edu. /files/1/1/2 006may-fri-055514. pdf.

[10] WOSP, 2013. Woreda office of population and statistics WOSP, 2013.

[11] FMOH, 2003a. Family Planning Extension Package. Addis Ababa, Ethiopia.
[12] Gujarati, D. N., 1995. Basic econometrics: (3rd ed.). New York, McGraw Hill, Inc.

[13] Yamane, T. 1967. Elementary Sampling Theory. Prentice-Hall, Inc.: London.

[14] Tewodros, D. and H. Damen, 2007. Determinants of conventional health service utilization among pastoralist in northeast Ethiopia. Student Research Program. Jimma University.

[15] Haile, D., 2007. Determinants of birth control methods use in Konta Special Wereda, Southern Ethiopia. Unpublished master's thesis, School of Graduate Studies, Haramaya University.

[16] Bonge, B., 2005. Knowledge, attitude and practice related to family planning among women in the reproductive age group in Assella Town, central Ethiopia. Student Research Program. Jimma University.

[17] Firaole, W., 2005. A cross sectional study on knowledge, attitude and practice of men of 15-65 year age group on family planning in Jimma Town, southwestern Ethiopia. Student Research Program. Jimma University.

[18] Amaha, H. and E. Fiqre, 2006. Influence of women's autonomy on couples contraception use in Jimma Town, southern Ethiopia. Ethiopian Journal of Health Development 20(3):135-205.

[19] Caldwell, J. C., K. Barakat, Caldwell, B., P, Piers I., Caldwell, P., 1999. The Bangladesh fertility Decline: An Interpretation. Population and Development Review 25(1):67-84.

[20] Maglad Nour E., 1994. Fertility in Rural Sudan: the Effect of land holding and Child Mortality. Economic Development and Cultural Change 41(4):761-783.

[21] Wegene, T. and E. Fiqre 2007. Knowledge, attitude and practice of emergency contraceptives among female university students in Addis Ababa, Ethiopia. Ethiopian Journal of Health Development 21(2):109-182.

[22] Jeeleebhoy, N. Shireen, (1995). Women's Education, Autonomy and Reproductive Behavior; An Experience from Developing Countries. First Edition. Oxford University Press. New York 235p.

[23] USAID, United States Agency International Development 1999. Women"s Empowerment in Agricultural Index, United STATES OF America.

[24] Belaineh, G., A. Demeke and T. Kora, 2004. Determinants of condom use among Agaro high school students using behavioral model. Ethiopian Journal of Health Development 18(1): 01-66.

[25] TilahunSeifu, 2008. Access To And Utilization Of Family Planning Information Among Rural Women In Adama District, Oromia National Regional State, Ethiopia.

[26] Asres, E., 2005. Access and utilization of development communication by rural women in Dire Dawa Administrative Council, Eastern Ethiopia. M.Sc. Thesis presented to the School of Graduate Studies of Haramaya University, Ethiopia. 